\title{
Radio Occultation Retrieval of Atmospheric Profiles from the FORMOSAT-3/COSMIC Mission: Early Results
}

\author{
Cheng-Yung Huang ${ }^{1, *}$, Chio-Zong Cheng ${ }^{2}$, Po-Hsiung Lin ${ }^{3}$, Chen-Joe Fong ${ }^{1}$, \\ Jens Wickert ${ }^{4}$, and Chun-Chieh Hsiao ${ }^{1}$ \\ ${ }^{1}$ National Space Organization (NSPO), Hsinchu, Taiwan, ROC \\ ${ }^{2}$ Plasma and Space Science Center, National Cheng Kung University, Tainan, Taiwan, ROC \\ ${ }^{3}$ Department of Atmospheric Science, National Taiwan University, Taipei, Taiwan, ROC \\ ${ }^{4}$ Helmholtz Centre Potsdam, GFZ German Research Centre for Geosciences, Potsdam, Germany
}

Received 27 June 2007, accepted 24 April 2008

\begin{abstract}
Six identical micro-satellites of the FORMOSAT-3/COSMIC (Formosa Satellite \#3 and Constellation Observing System for Meteorology, Ionosphere and Climate: FS-3/C) mission were successfully launched on 14 April 2006. The FS-3/C mission provides the first satellite constellation for monitoring global weather using the Global Positioning System (GPS) radio occultation (RO) technique. The mission's primary scientificific goal is to obtain near-real time profiles of the bending angle and refractivity in the neutral atmosphere and in the ionosphere. In April, 2007 the FS-3/C mission provide about RO soundings of 2000 atmospheric vertical profiles per day in a nearly uniform distribution around the globe. The lowest altitude penetration for more than $80 \%$ of RO soundings reached below $1 \mathrm{~km}$ in altitude. Most soundings have penetration below $800 \mathrm{~m}$ altitude in the equatorial region and below $200 \mathrm{~m}$ altitude in polar regions. The quality and accuracy of the RO sounding profiles are in good agreement with the CHAMP (CHAllenging Minisatellite Payload) RO soundings and direct measurements using dropsondes. The FS-3/C RO sounding observations are used to support operational global weather prediction, climate monitoring and research, space weather forecasting, and ionosphere and gravity research.
\end{abstract}

Key words: FORMOSAT-3, COSMIC, Occultation, GPS

Citation: Huang, C. Y., C. Z. Cheng, P. H. Lin, C. J. Fong, J. Wickert, and C. C. Hsiao, 2009: Radio occultation retrieval of atmospheric profiles from the FORMOSAT-3/COSMIC mission: Early results. Terr. Atmos. Ocean. Sci., 20, 21-34, doi: 10.3319/TAO.2008.04.24.01(F3C)

\section{INTRODUCTION}

Six identical micro-satellites comprising the FS-3/C (Formosa Satellite \#3 and Constellation Observing System for Meteorology, Ionosphere and Climate) mission were successfully launched into low-earth orbit from Vandenberg Air Force Base, California on 14 April 2006 (Cheng et al. 2006). The FS-3/C mission provides the first satellite constellation for monitoring global weather using the Global Positioning System (GPS) radio occultation (RO) technique. The mission is a Taiwan-US collaborative project jointly carried out by the National Space Organization (NSPO) in Taiwan and the University Corporation for Atmospheric Research (UCAR) in the United States. During a deployment period of $\sim 16$ months, each satellite will rise to its final orbit

* Corresponding author

E-mail:yusn2845@gmail.com at an altitude of $\sim 800 \mathrm{~km}$, an orbit plane inclination angle of 72 degrees, and a separation angle between the neighboring orbit planes of 30 degrees longitude. The satellites are expected to operate for 5 years. The mission's scientific goal is to obtain near real time profiles of a bending angle, refractivity, temperature, pressure and water vapor in the neutral atmosphere and electron density in the ionosphere. The observations will be used to support operational global weather prediction, climate monitoring and research, space weather forecasting, and ionosphere and gravity research (Rocken et al. 2000; Wu et al. 2005a).

There are three science payloads on each satellite: a GPS Occultation Experiment (GOX) payload, a Tiny Ionospheric Photometer (TIP), and a Tri-Band Beacon (TBB) payload as shown in Fig. 1. The GOX payload is used to obtain radio occultation (RO) sounding of vertical profiles of 


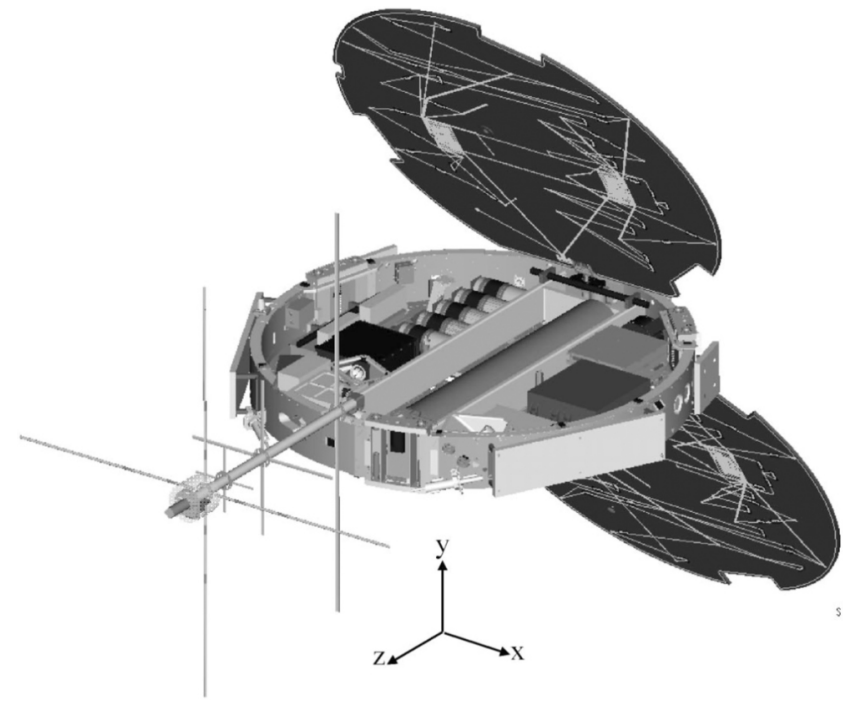

Fig. 1. A FS-3/C satellite and its science payloads: GPS Radio Occultation Experiment (GOX), Tiny Ionospheric Photometer (TIP) and Tri-Band Beacon (TBB). The occultation and POD (Precision Orbit Determination) antennas are in the $\mathrm{x}-\mathrm{z}$ plane and are inclined to nadir and zenith, respectively. The TIP port and the TBB antenna point to the nadir direction. The solar panels open up in the $y-z$ plane after the launch of satellites.

refractivity which is a function of temperature, pressure and water vapor of the lower atmosphere and electron density in the ionosphere. The TIP and TBB are used to obtain information of the ionospheric electron density. In this paper we report the status of the GOX and the quality of the atmospheric data. We also present a comparison of RO sounding data with dropsonde measurements of atmospheric profiles made during an Intensive Observation Period (IOP) campaign in 2006.
The GOX receiver measures the propagation time of radio signals from GPS satellites to FS-3/C satellites. As radio waves pass through the atmosphere, they are refracted and slowed, with the degree of bending related to the pressure, temperature and water vapor in the atmosphere and electron density in the ionosphere (Fig. 2). From the raw phase and amplitude measurements, we can deduce vertical profiles of bending angles at the ray perigee point. With the assumption of local spherical symmetry, a vertical profile of refractivity can be retrieved using the Abelian inversion technique. The vertical profiles of bending angles or refractivity can be assimilated into numerical weather prediction models, yielding information on temperature, pressure and water vapor. Vertical profiles of temperature and moisture can be deduced from refractivity profiles with the use of ancillary information. Further information on the RO technique and the FS-3/C mission were presented in a special TAO issue (2000).

The GOX makes use of an advanced signal tracking technique known as open-loop (OL) tracking. With OL tracking, the RO soundings will penetrate deep into the lower troposphere at all latitudes and longitudes observing planetary boundary layer heights and structure and providing valuable information on low-level moisture (Sokolovskiy et al. 2006a).

In the FS-3/C mission goal, the GOX is designed to provide over 2500 atmospheric soundings every 24 hours in a nearly uniform distribution around the globe as shown by green dots in Fig. 3. This is considerably higher than the number of present world-wide daily radiosonde observations ( $\sim 1500$ soundings from $\sim 850$ stations) as shown by gray dots in Fig. 3, which are concentrated mostly over land areas. The RO soundings' high vertical resolution will com-

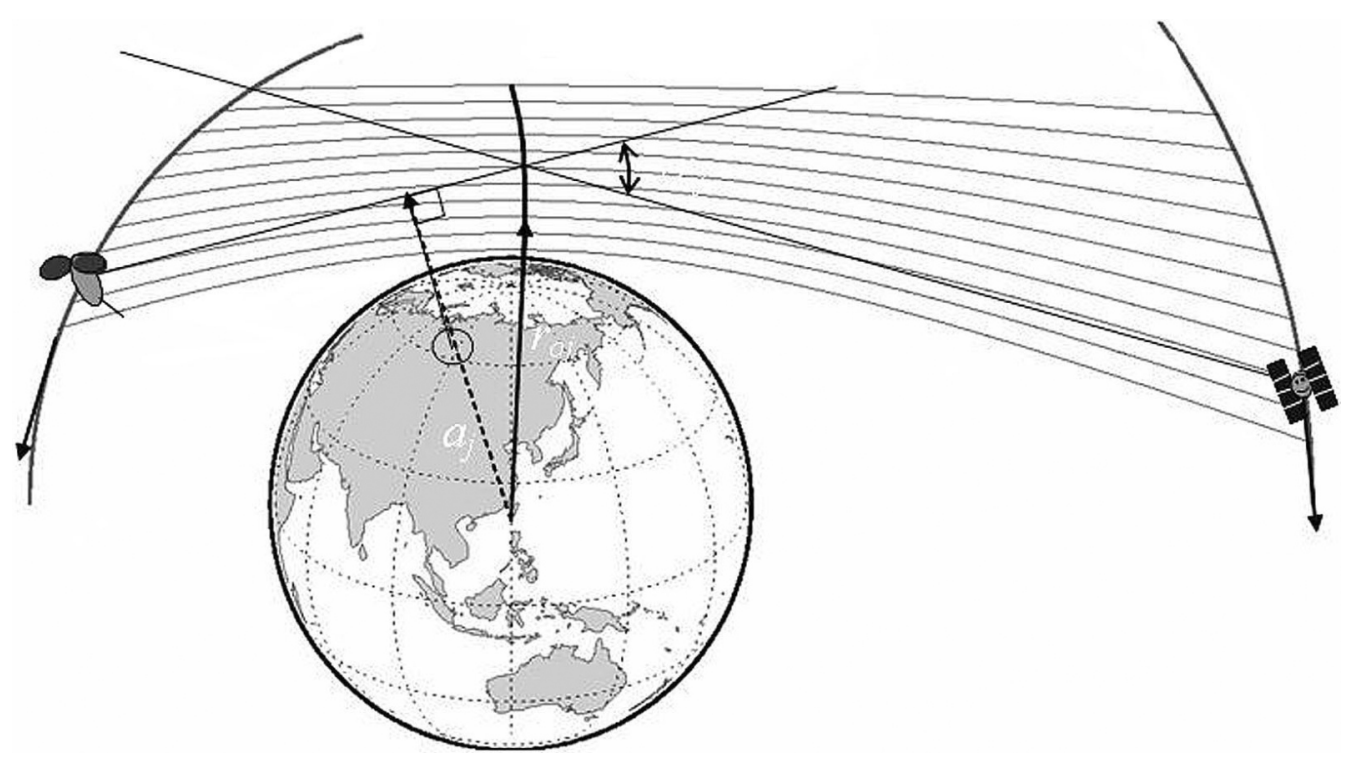

Fig. 2. Radio occultation of GPS signals emitted from the GPS satellite. The blue perigee curve represents a vertical profile. 


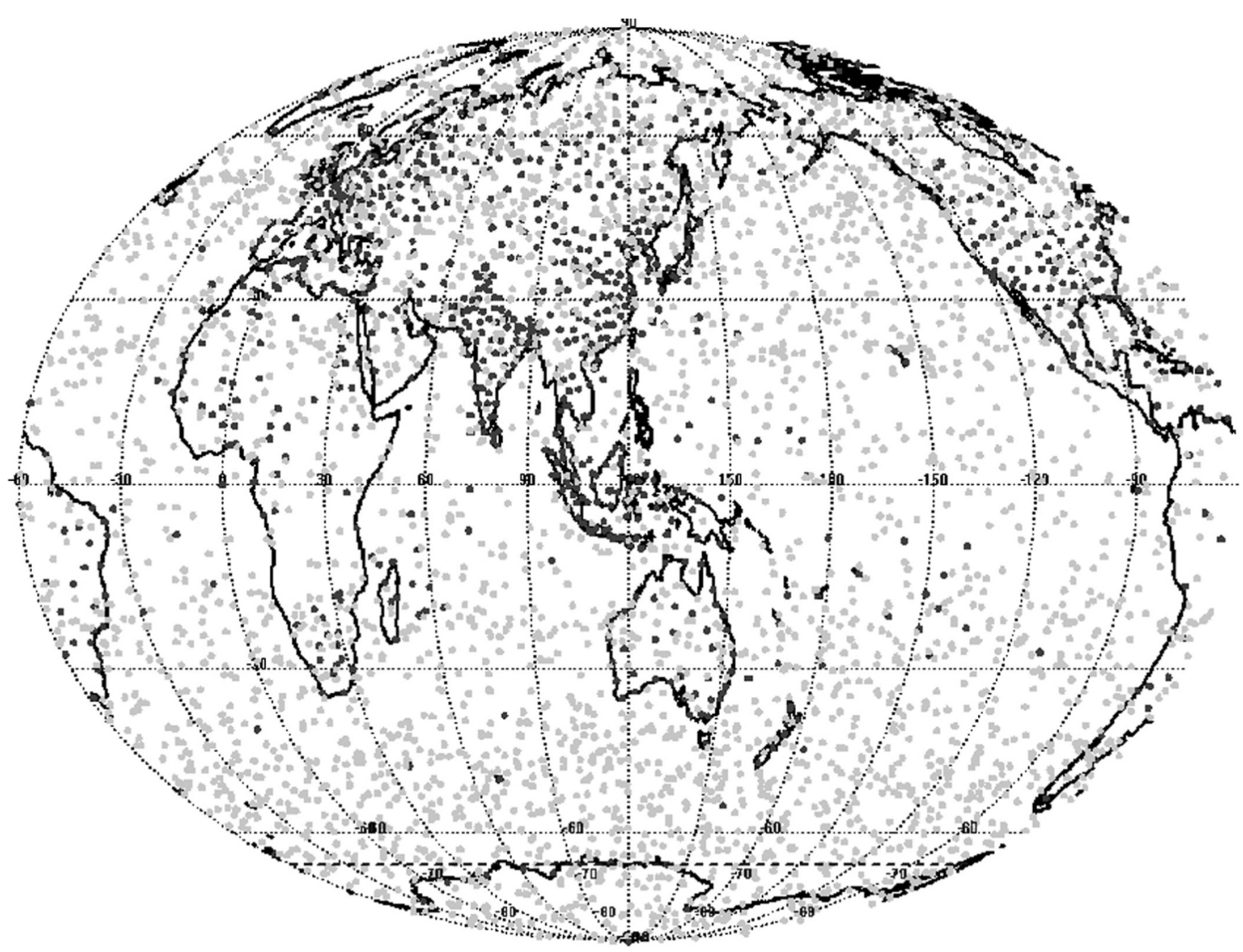

Fig. 3. Over 2500 RO soundings (gray dots; each dot represents the location of RO sounding) are obtained by GOX receivers each day. Black dots indicate the location of the present world-wide $\sim 850$ radiosonde stations.

plement the high horizontal resolution of conventional infrared and microwave satellite soundings. The GOX will also obtain the Total Electron Content (TEC) along the GPS ray-path and the vertical profile of the electron density. The $\sim 2500$ electron density profiles between 90 and $800 \mathrm{~km}$ will define the ionospheric structure, scintillation and electron density irregularities.

In this paper we report early results of RO soundings of vertical atmospheric profiles of the FS-3/C mission. In Section II we describe the status of early RO soundings and comparison with CHAMP results (Wickert et al. 2001, 2006). In Section III we describe the results of an Intensive Observation Period (IOP) campaign to cross-validate the accuracy of refractivity profiles of the FS-3/C RO soundings by comparing with refractivity profiles obtained by using the atmospheric measurement from the dropsonde experiment during an IOP campaign. In Section IV we discuss the possible error source of the FS-3/C RO sounding profiles. A summary is given in Section $\mathrm{V}$.

\section{RADIO OCCULTATION SOUNDINGS}

Since the FS-3/C satellites were launched, more than 400000 atmospheric vertical profiles and 600000 iono- spheric vertical electron density profiles had been extracted from the radio occultation (RO) measurements since 30 April 2007. The FS-3/C RO sounding data presented in this paper was downloaded from the Taiwan Analysis Center for

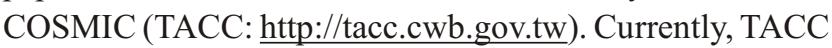
RO software is supported by UCAR, and the data processing software will be identical to CDAAC's.

The number of atmPhs files (open diamonds) and the number of atmPrf files (solid circles) per day are plotted in Fig. 4. The number of atmPhs files means the number of RO events observed, and the number of atmPrf files means the number of RO events that could be retrieved to provide atmospheric profiles. The atmPrf files include an index for data quality, and only profiles marked as good data are included in the number count. The good data profiles are determined by the high and low boundaries in altitude, phase fluctuation in GPS signals, and the refraction bias with the atmospheric model. The number of RO retrieval measurements of vertical profiles per day has been increasing with time during the deployment phase of the FORMOSAT-3 satellite orbits. The number of RO sounding profiles is about 1800 /day for the neutral atmosphere and 3000/day for the ionosphere by April, 2007. However, the total daily number of GPS excess phase measurements by the GOX in- 


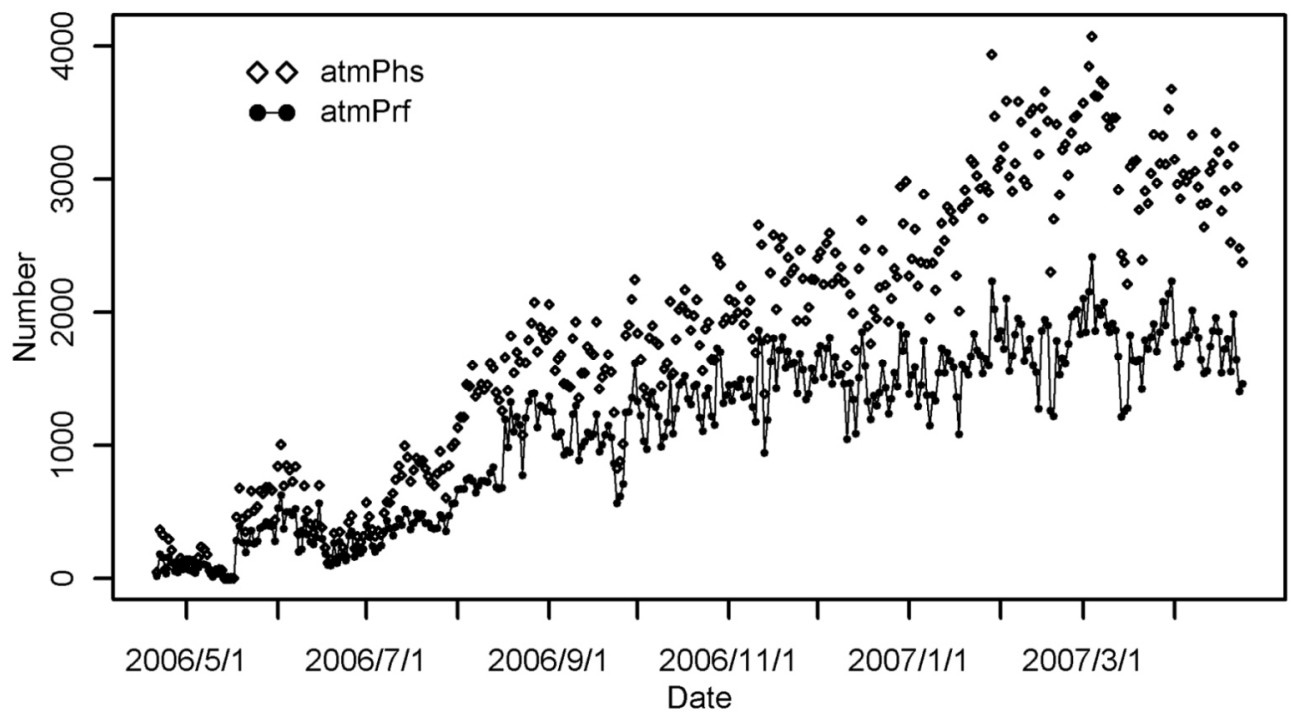

Fig. 4. The total number of atmospheric RO sounding profiles (atmprf, solid circles) per day obtained by FORMOSAT-3 satellites versus date. The open diamonds (atmPhs) show the total number of GPS excess phase measurements that can be computed from the GPS signals received by FORMOSAT-3 satellites.

struments has also been increasing as shown by the open diamonds in Fig. 4, indicating that the unsuccessful RO retrieval events were also increasing. The RO sounding profiles are less than the number of GPS excess measurements because some GPS excess measurements could not be retrieved to obtain RO sounding profiles. The increase in the total daily RO events from July, 2006 is mainly associated with the upload of a new OPEN LOOP firmware (version 4.3) for the satellite GOX system one-by-one from 13 July 2006 for several days and the daily RO event number took a large increase in August. There is a considerable increase in the atmPhs data due to the new firmware upload, but the percentage that atmPhs files were retrieved to obtain atmPrf files did not increase. It means the firmware could track more rising RO data, but the data quality is not good enough to be retrieved to obtain atmospheric profiles. The firmware needs to be improved further.

The white curves in Fig. 5 show the FORMOSAT-3 satellite orbits on 23 April 2007. The orbits of three satellites (FM\#1, FM\#3, and FM\#4) are nearly superimposed (the left white curves in Fig. 5). Two satellites (FM\#1 and FM\#3) are still in a temporary parking orbit (at $\sim 515 \mathrm{~km}$ altitude), FM\#4 was just raised to the mission orbit and started to separate from the FM\#1 and FM\#3 satellites due to different precession rate at different altitude. The orbital planes of other satellites (FM\#2, FM\#5, and FM\#6) were raised much earlier and are separated by 30 degrees in longitude. The white dots in Fig. 5 show the locations of the atmospheric RO sounding profiles in one day with 1405 RO events, which shows the FS-3 satellites' capability to observe atmosphere globally, especially over oceans and polar regions. With the FS-3 satellite orbit constellation on 23

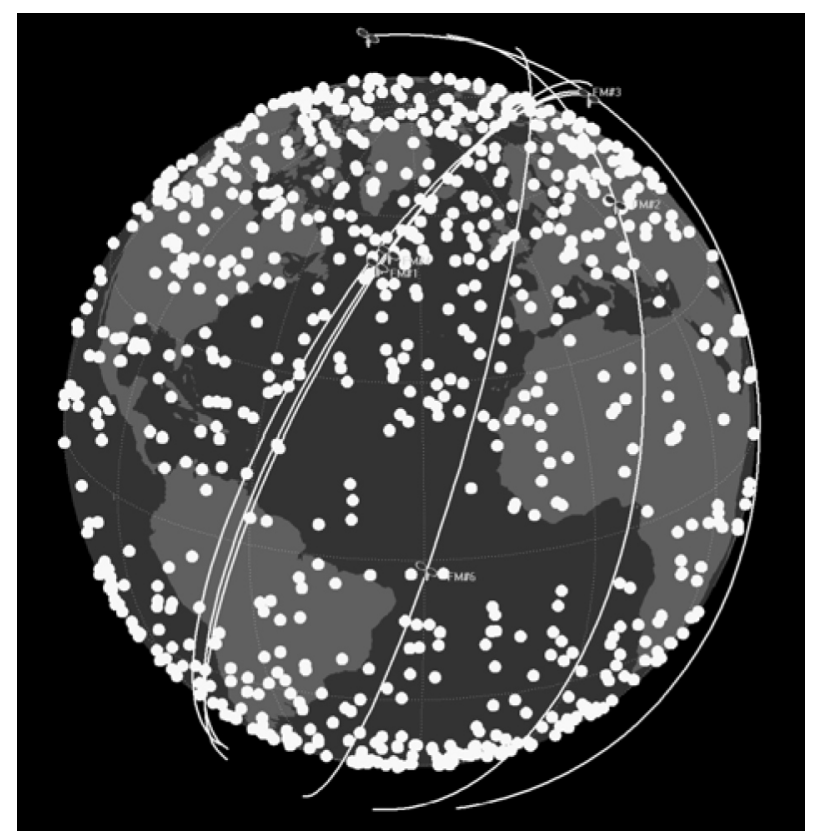

Fig. 5. Orbits (white curves) of FORMOSAT-3 satellites on 29 April 2007. The white dots indicate the RO sounding locations in one day.

April 2007, the RO retrieval events were concentrated in two time periods per day as shown in the lower panel of Fig. 6 which shows the hourly RO retrieval event number versus time for events within circles with a $2500 \mathrm{~km}$ radius centered at 120 degrees Longitude and at zero degrees latitude (the dotted and dashed line), at 25 degrees latitude (solid line), and at 50 degrees latitude (dotted line), respectively. After the deployment of all six satellite orbits is finished, the RO 

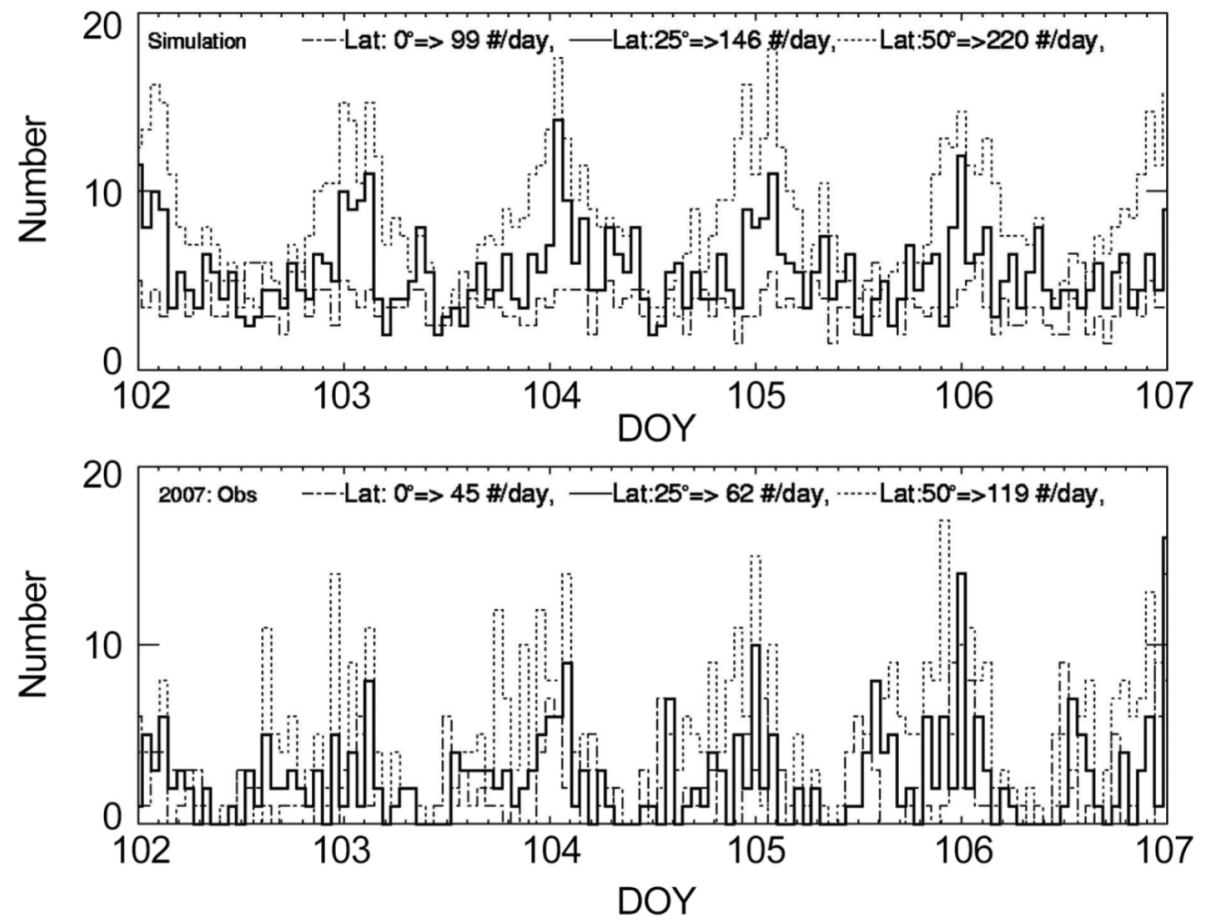

Fig. 6. Hourly RO retrieval event number versus time. The lower panel shows the number of retrieval events from 23 - 29 April 2007 . The upper panel shows the number of retrieval events obtained by simulation assuming that all six FORMOSAT-3 satellites are in the planned final orbits. The dash-dotted (solid, dotted) curves are the hourly event number within a circle area centered at $0(25,50)$ degree Latitude and 120 degree Longitude with a radius of $2500 \mathrm{~km}$.

events will spread out more evenly as shown in the upper panel (obtained by simulation) in Fig. 6.

During the first few months after the FS-3 satellite launch the satellite orbits were very close to each other and stay almost in an orbital plane. It was the best time to verify that the GOX equipments on all FS-3 satellites all functioned properly and consistently. When all satellites were close to each other, it was more probable for all six satellites to obtain RO retrieval profiles for the same area and at about the same time. Figure 7 shows the results of one such case on 7 May 2006. All six FS-3 satellites received GPS signals that had very close paths from the same GPS satellite. Therefore, if the maximum horizontal separation distance between RO profiles (GPS ray tangent points) is less than 100 kilometer and the maximum RO retrieval time difference is less than two minutes, these RO events would be compared in this statistics of Fig. 7. The right panel of Fig. 7 shows the difference between the refractivity profile (labeled as C001) obtained by the FM\#1 satellite and the refractivity profiles (labeled as C002 - C006) obtained on 7 May 2006 by the other five FORMOSAT-3 satellites FM\#2 - FM\#6, respectively. The refractivity obtained by different FORMOSAT-3 satellites is quite similar and their differences are larger below $3 \mathrm{~km}$ latitude. Shown in the right panel of Fig. 7 are the dry temperature profiles (labeled as C001 - C006) obtained by all six FORMOSAT-3 satellites. Except for the FM\#6 satellite, the profiles of dry temperatures and refractivity from all other satellites are in good agreement for altitudes above five kilometers. The dry temperature obtained by the FM\#6 satellite is larger than others because the FM\#6 GOX receiver has an older version of firmware than other FS-3 satellites and it did not allow the FM\#6 satellite's antenna to track well with the GPS signal Doppler shift at higher altitudes. The problem happens sometimes in rising RO events. This problem was corrected after the GOX firmware of all six FS-3 satellites was updated around 12 July 2006.

To evaluate the quality of FS-3 GOX instruments, we performed statistical analysis of the GOX RO data for the period from 16 April to 30 September 2006. The RO events obtained by the FM\#2 - FM\#6 satellites were chosen for analysis if they satisfied the conditions that the RO profile locations (tangent points) of FM\#2 - FM\#6 satellites were within $100 \mathrm{~km}$ in the horizontal direction from the RO profile position of FM\#1 satellite location and the RO events were measured within one hour from the FM\#1 RO measurement. In all, about 20000 RO events satisfy the constraints. In the left panel of Fig. 8, the solid line shows the bias of the fractional refractivity difference $[100 *$ (C002 $\mathrm{C} 001) / \mathrm{C} 001$, etc.] relative to the $\mathrm{FM} \# 1$ refractivity profiles (C001), the dotted lines show the standard deviation of the fractional refractivity difference relative to the bias, and the dash line shows the number of RO events for refractivity comparison versus different altitude. Note that the number of RO events decreases as the lowest altitude penetration of 

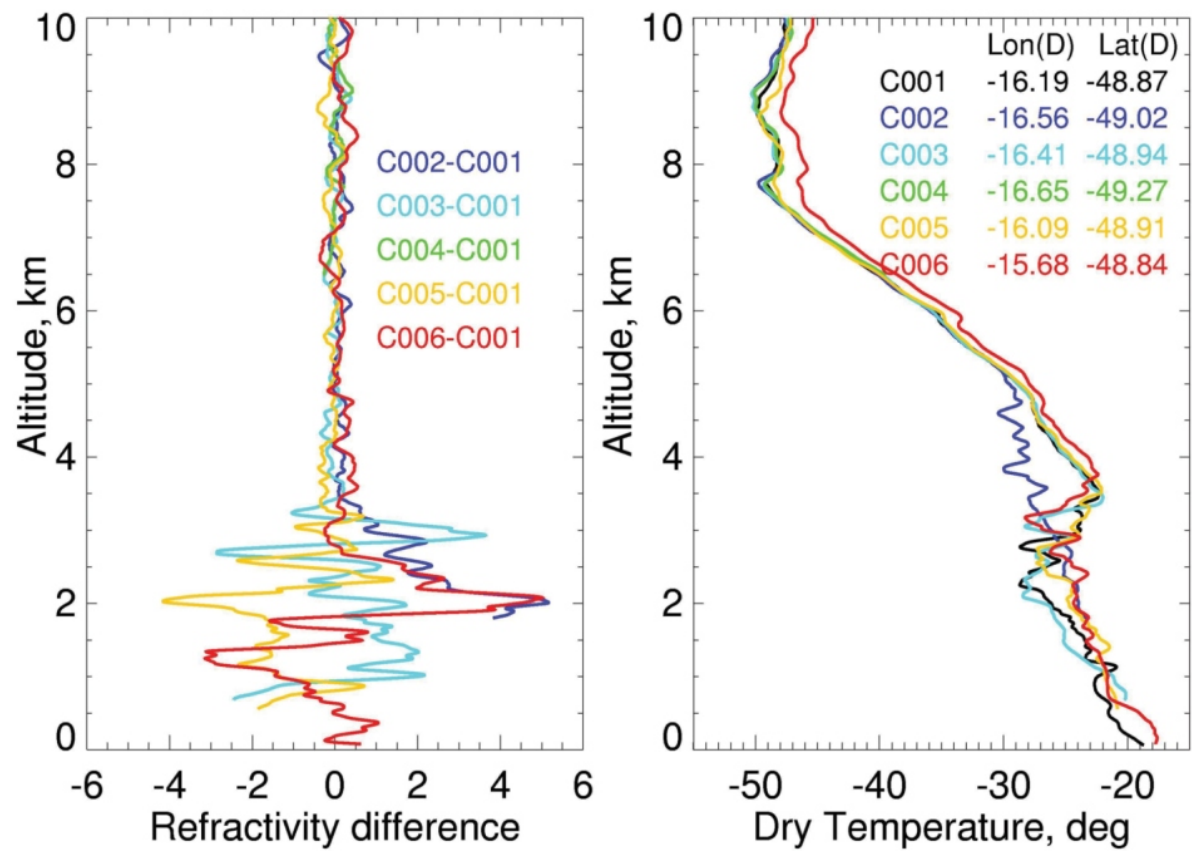

Fig. 7. The left panel shows the difference between the refractivity profile obtained by the first FORMOSAT-3 satellite (labeled as C001) and those obtained by the other five FORMOSAT-3 satellites (labeled as C002 - C006) on 7 May 2006. The right panel shows the dry temperature profiles obtained by all FORMOSAT-3 satellites. All six satellites remained very close to each other on 7 May 2006 which is about 3 weeks after the launch of FORMOSAT-3 satellites.
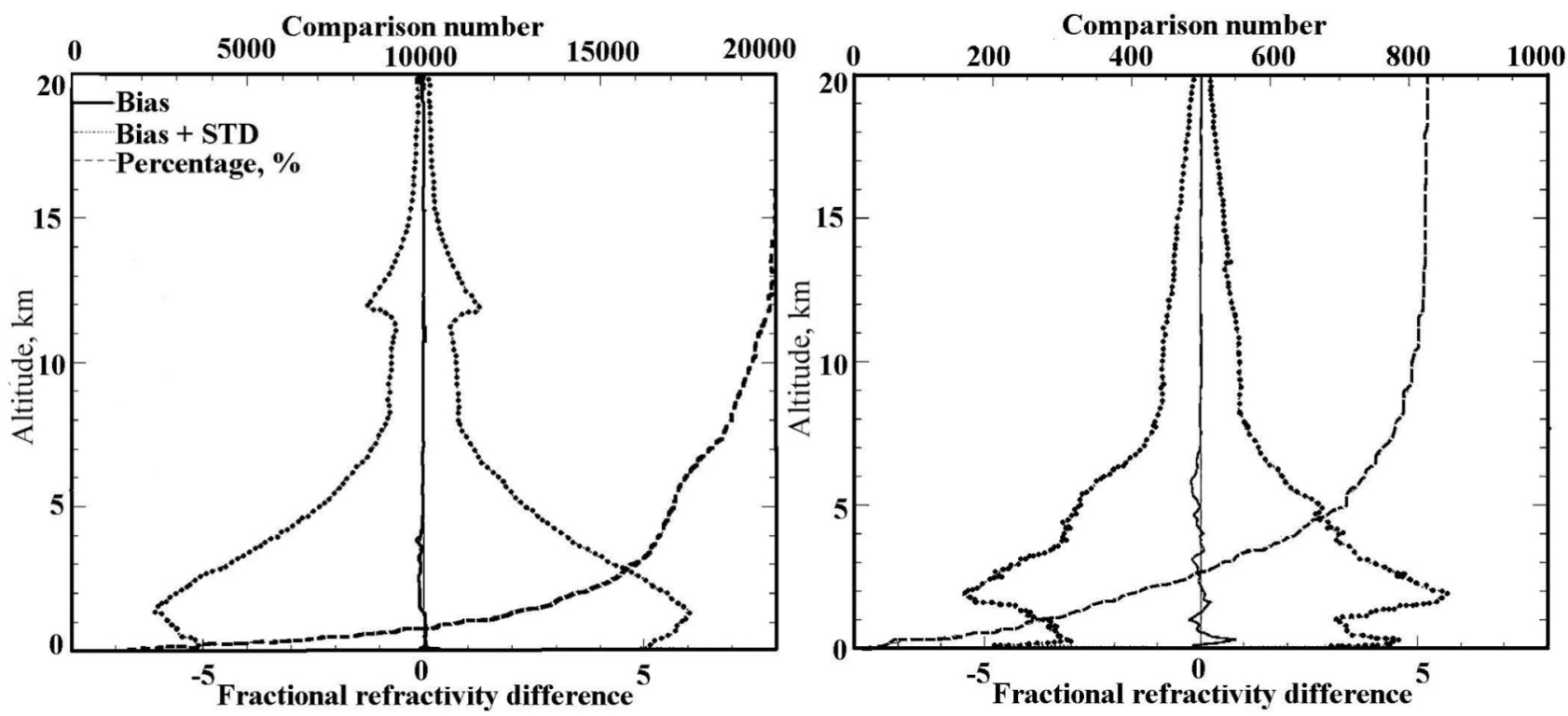

Fig. 8. The left panel shows the bias and standard deviations from the statistics for the fractional difference [i.e., $100 *(\mathrm{C} 002$ - C001)/ C001, etc.] between the refractivity profile obtained by the first FORMOSAT-3 satellite (C001) and those obtained by the other FORMOSAT-3 satellites (C002 - C006) when their profile locations are within $100 \mathrm{~km}$ in horizontal direction from the first satellite and the RO events are measured within one hour from the first satellite RO measurement. The events covered in the statistics were obtained from 16 April to 30 September 2006 . The dashed curve shows the total number of RO events used in computing the bias and standard deviations. The comparison between the CHAMP soundings and the FORMOSAT-3 RO soundings is shown in the right panel with the same criteria. The events were obtained from 1 January to 10 May 2007.

RO sounding profiles decreases. The bias shows that the refractivity profiles observed by different FS-3 satellites are consistent among each other with a small variation between 2 and $5 \mathrm{~km}$ altitude. Although the bias is very small, the standard deviation below $5 \mathrm{~km}$ altitude is somewhat large with a value of $6 \%$ at around $1.5 \mathrm{~km}$ altitude. The large standard de- 
viation below $5 \mathrm{~km}$ altitude may be caused by complex atmospheric conditions or the assumptions made in the retrieval scheme such as the spherical symmetry of the atmosphere.

To evaluate the quality of FS-3 RO soundings relative to the CHAMP measurements, we perform a statistical analysis using data for the period from 1 January to 10 May 2007. The CHAMP RO sounding data are downloaded from the Taiwan Analysis Center for COSMIC (TACC: http://tacc .cwb.gov.tw). The FS-3 RO events were chosen for the analysis if the FS-3 sounding locations (GPS ray tangent points) were within $100 \mathrm{~km}$ in a horizontal direction from the CHAMP sounding locations and the FS-3 RO events were measured within one hour from the CHAMP RO measurement. In total, there are over 800 FS-3 RO events which satisfied the requirements. In the right panel of Fig. 8 the solid line shows the bias of the fractional difference of FS-3 refractivity profiles relative to the CHAMP refractivity profiles, and the dotted lines show the standard deviation of the fractional difference relative to the bias and the dashed line shows the number of RO events for refractivity comparison versus different altitude. The bias (CHAMP - COSMIC) between FS-3 and CHAMP refractivity profiles are consistent. The Standard deviation is as large as in the lower panel of Fig. 8. There is a peak around $12 \mathrm{~km}$, which is due to some bad RO profiles with their bottom altitude at $\sim 12 \mathrm{~km}$. The reason for these bad RO profiles is still not clear necessitating more study to understand this feature.

Note that the CHAMP RO retrieval profiles were obtained by using the CLOSE LOOP technique. The OPEN LOOP scheme allows RO retrieval even when the received GPS signal is weak or is interfered by the multi-path effects, but the CLOSE LOOP technique allows RO retrieval only when the received GPS signal is reasonably clear. The detailed description of the different functions between CLOSE
LOOP and OPEN Loop has been discussed by Sokolovskiy et al. (2006b). Thus, when a CHAMP RO sounding can reach below $5 \mathrm{~km}$, its RO soundings should have as good a quality as the FS-3/C RO soundings.

Before the development of the OPEN LOOP scheme for RO retrieval of atmospheric profiles, the lowest altitude of vertical profiles of the retrieved atmospheric quantities was too high, and the ability to retrieve atmospheric quantities below $5 \mathrm{~km}$ altitude was quite limited [see for example, the results of CHAMP (Beyerle et al. 2006) and MicroLab-1 satellites (Gurvich et al. 2006)]. Adopting the Open Loop technique developed by the Jet Propulsion Laboratory, the FORMOSAT-3 GOX receivers are able to retrieve atmospheric profiles down to quite low altitudes. Figure 9 shows the global distributions of the lowest altitude penetration of the RO sounding profiles obtained by FORMOSAT-3 satellites (135312 profiles, in all) and the CHAMP satellite (9512 profiles in total) for the period from 1 January to 10 May 2007. Over land, the profile penetration is limited by orography. Thus, we separate the RO sounding profiles into two groups: one group is over the ocean and the other group is over the land. In Fig. 9, the upper and lower panels show the distribution of the lowest altitude penetration of the RO retrieval profiles of the land group obtained by the FS-3 and CHAMP satellites. Here the altitude is measured from the earth surface. We note that they are mostly below $0.5 \mathrm{~km}$ in the southern polar region. In most other land regions the lowest altitudes are all below $1 \mathrm{~km}$. Those with lowest altitude above $1 \mathrm{~km}$ are mostly located in mountainous areas such as Himalayas, Tibetan highlands, and Andes mountains in the South America because high mountains prevent GPS RO signals with a lower perigee point altitude from being detected. Moreover, the lowest altitude penetration of CHAMP RO soundings is significantly higher than the FS-3
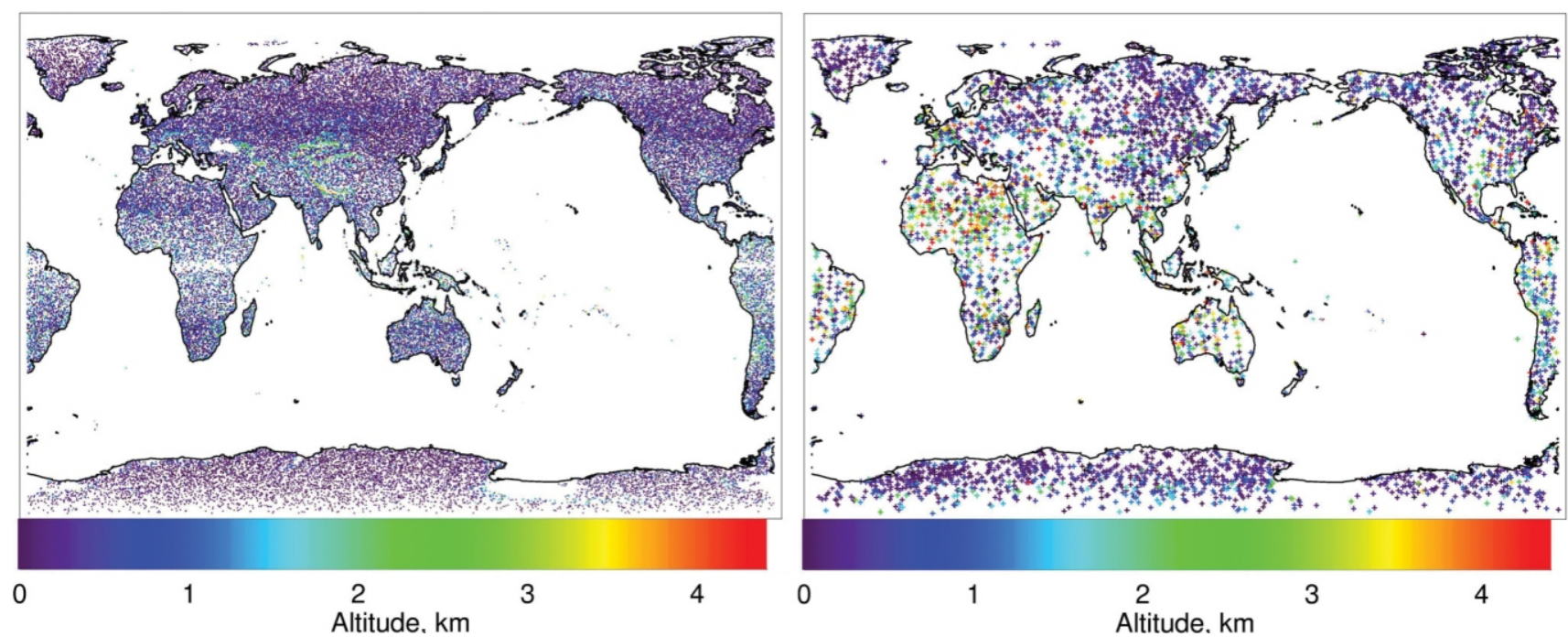

Fig. 9. The left and right panels show the distribution of the lowest altitude penetration (indicated by colors) of RO soundings above land areas obtained by FORMOSAT-3 satellites and CHAMP, respectively. The altitude is measured from the earth surface for both cases. 
RO soundings in an equatorial region. Note that because of the relatively high inclination of the FS-3 satellite orbits, the number of RO sounding events in an equatorial region is much less than the RO event number in an high latitude region. We see that the lowest retrieval altitude penetration is lower in a southern polar region and is higher in an equatorial region in comparison with other ocean areas for both FS-3 and CHAMP data. Also, the lowest altitude penetration of CHAMP RO soundings is significantly higher than the FS-3 RO soundings in equatorial and southern mid-latitude regions. Note that the penetration of CHAMP RO soundings can reach below $2 \mathrm{~km}$ mainly from a higher latitude.

Figure 10 shows the altitude versus the percentage of RO sounding events that penetrate to or below the altitude value for the FORMOSAT-3 and CHAMP RO sounding events. The RO sounding events covered in computing the statistics are obtained from 1 January to 10 May 2007. In the left panel, the altitude is measured from the earth's surface and the statistics are computed for total events and for events over oceans for FORMOSAT-3 and CHAMP separately. We see that more than $80 \%$ of the RO events (in which $50 \%$ of the RO events occur over oceans and $30 \%$ of RO events over land areas) have the lowest altitude penetration equal or below $1 \mathrm{~km}$ for the FS-3 events, but only 50\% (30\% are over oceans and $20 \%$ are over land areas) for the CHAMP events. The right panel of Fig. 10 shows the accumulated percentage of RO events versus altitude for RO sounding events over land areas with the altitude measured from the earth's surface (labeled as ES) and the sea level (labeled as SS) separately.

To understand the effect of the specific humidity on the lowest altitude penetration of the RO sounding profiles, we present, in Fig. 11, the statistics of the lowest altitude penetration versus latitude for the FS-3 and CHAMP RO sounding events discussed concerning Fig. 10. In Fig. 11 the left panel was obtained from the FORMOSAT- 3 RO events and the right panel was obtained from the CHAMP RO events. The solid line represents the lowest altitude penetration for a median number of events, i.e., $50 \%$ of the sounding profiles have the lowest altitude below the altitude given by indicated by a solid curve. Similarly, the dashed line represents the first quartile number of lower altitude penetration events, and the dash-dotted line represents the third quartile number of events. For the median number of events the lowest altitude penetration is $0.3 \mathrm{~km}$ in the northern polar region, $0.1 \mathrm{~km}$ in the $70^{\text {th }}$ degree latitude in the southern polar region, $0.5 \mathrm{~km}$ in a mid-latitude region, and about $1 \mathrm{~km}$ in an equatorial region. The results for CHAMP data are shown in the right panel of Fig. 11, and for the median number of events the lowest altitude penetration is $0.5 \mathrm{~km}$ in a polar region and $2-3 \mathrm{~km}$ in an equatorial region. The results clearly show that using the Open Loop technique the FS-3 RO events have lower altitude penetration than CHAMP events which were obtained using the Closed Loop technique. Moreover, for the third quartile number of events, the lowest
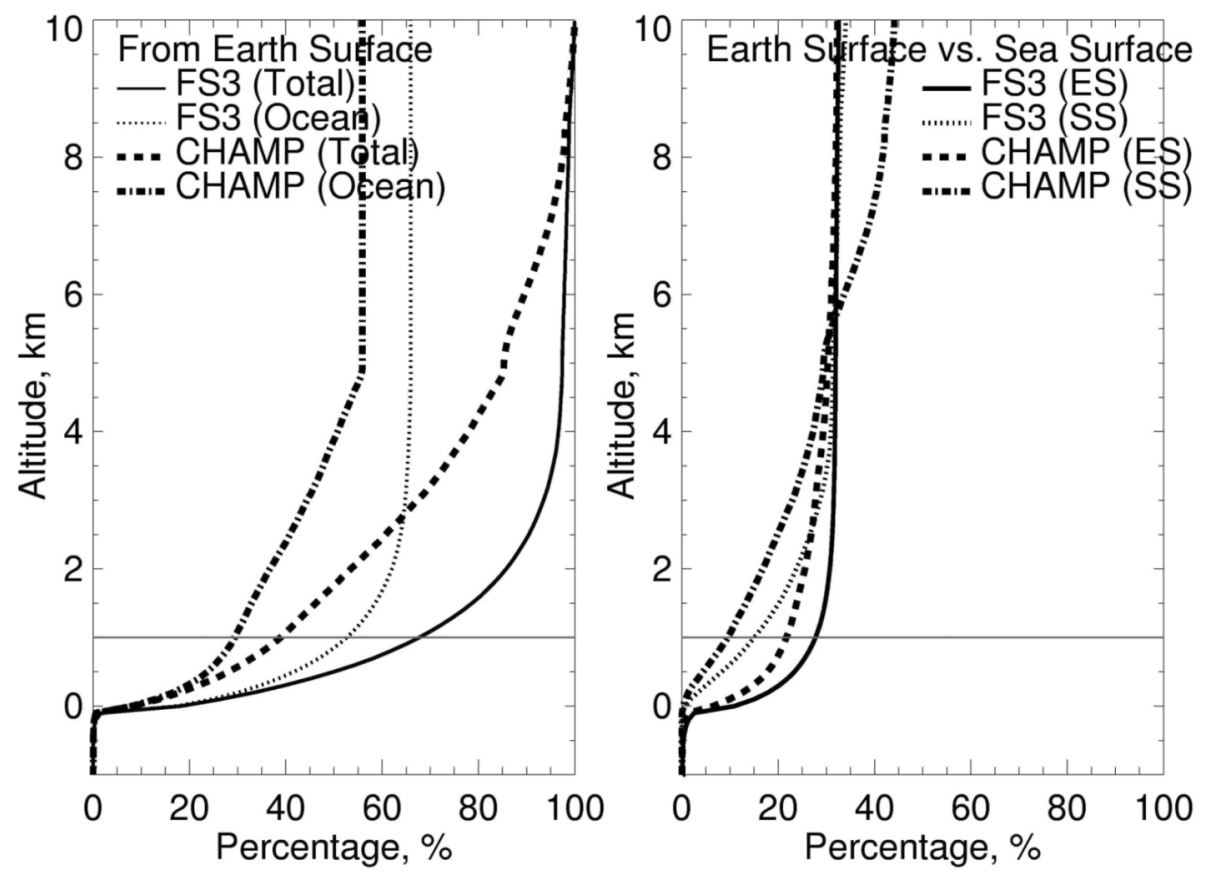

Fig. 10.The altitude versus the percentage of RO sounding events that have the lowest altitude penetration equal or below the altitude. The FORMOSAT-3 and CHAMP RO events covered in the statistics are obtained from 1 January to 10 May 2007. In the left panel the altitude is measured from the earth surface and the statistics are computed for the total events and for events over oceans for FORMOSAT-3 and CHAMP, separately. The right panel shows the statistics for events above land areas with an altitude measured from the earth surface (labeled as ES) and the sea level (labeled as $\mathrm{SS})$, respectively. 


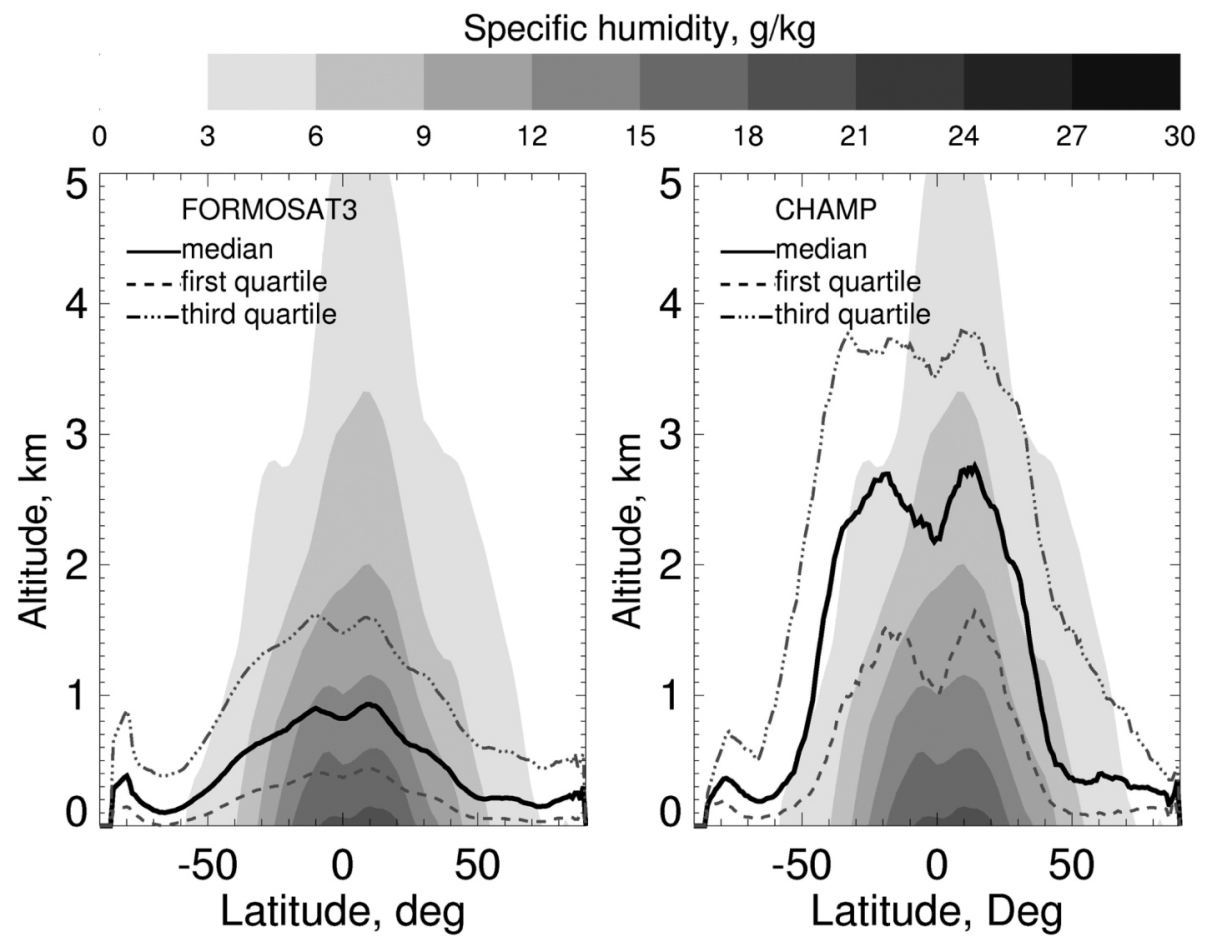

Fig. 11. The lowest altitude penetration versus latitude for RO events obtained from 1 January to 10 May 2007. The left and right panels are obtained from the FORMOSAT-3 and the CHAMP RO events, respectively. The solid line represents the median value of the lowest altitude penetration, the dashed line represents the first quartile value, and the dash-dotted line represents the third quartile value. Also shown is the water vapor specific humidity distribution in altitude and latitude (contour value is shown by color bar). The specific humidity is obtained by averaging over the month of March from 1968 to 1996 at 0 degree Longitude based on the NCEP model.

altitude penetration is about $1.6 \mathrm{~km}$ in an equatorial region for the FS-3 events and much lower than $3.8 \mathrm{~km}$ for CHAMP events. To find the correlation of the lowest altitude penetration of RO events with regard to water vapor we also show the specific humidity distribution in altitude and latitude (the contour value is shown by a color bar) along the zero degree longitude, which is obtained by averaging the specific humidity over the month of March from 1968 to 1996 based on the NCEP (National Center for Environmental Prediction) model. Excluding the RO data in the polar region, we find that the lowest RO altitude penetration is roughly proportional to the specific humidity. Thus, our result confirms the common perception that the penetration of RO is highly related to moisture distribution. Both the lowest RO altitude and the NCEP specific humidity are larger in a low latitude region. Thus, the water vapor is an important factor in determining the lowest altitude penetration of GPS RO retrieval of atmospheric vertical profiles.

\section{THE INTENSIVE OBSERVATION PERIOD (IOP) CAMPAIGN}

In order to perform cross data validation between the GPS RO sounding profiles and direct measurements of atmospheric profiles, we carried out an Intensive Observa- tion Period (IOP) campaign in 2006. Specifically we performed dropsonde measurements and compared the direct measurement results with FS-3 RO retrieval profiles. The comparison between the FS-3 RO sounding profiles and the radiosonde measurements have been reported by Wang and Lin (2007) and will not be reviewed here; however, comparisons between dropsonde and FS-3 soundings have not been reported, thus we report case studies supported by the IOP campaign during typhoons in this paper, as found in Figs. 12 and 13, respectively. The left panel of Fig. 12 shows the locations of the dropsonde measurements (open circles marked as D1 and D2) and the FS-3 RO events (solid circles marked as $\mathrm{C} 1$ and $\mathrm{C} 2$ ) performed on 29 October 2006. The distances between the dropsonde measurements and the FS-3 RO events were at about $100 \mathrm{~km}$ with a time difference of about one hour. The left figure in the right panel of Fig. 12 shows a comparison between the refractivity profiles obtained from atmospheric parameters measured by dropsondes and the refractivity profiles obtained by the closest FS-3 RO retrieval. The refractivity obtained from the dropsonde measurements was computed using the empirical formula given in Eq. (1) by Anthes et al. (2000), where the refractivity, $N$, is related to atmospheric parameters by which $N=77.6 P / T+3.73 \times 10^{5}$ $e / T^{2}$, where $T$ is the temperature in Kelvin, $P$ and $e$ are the 

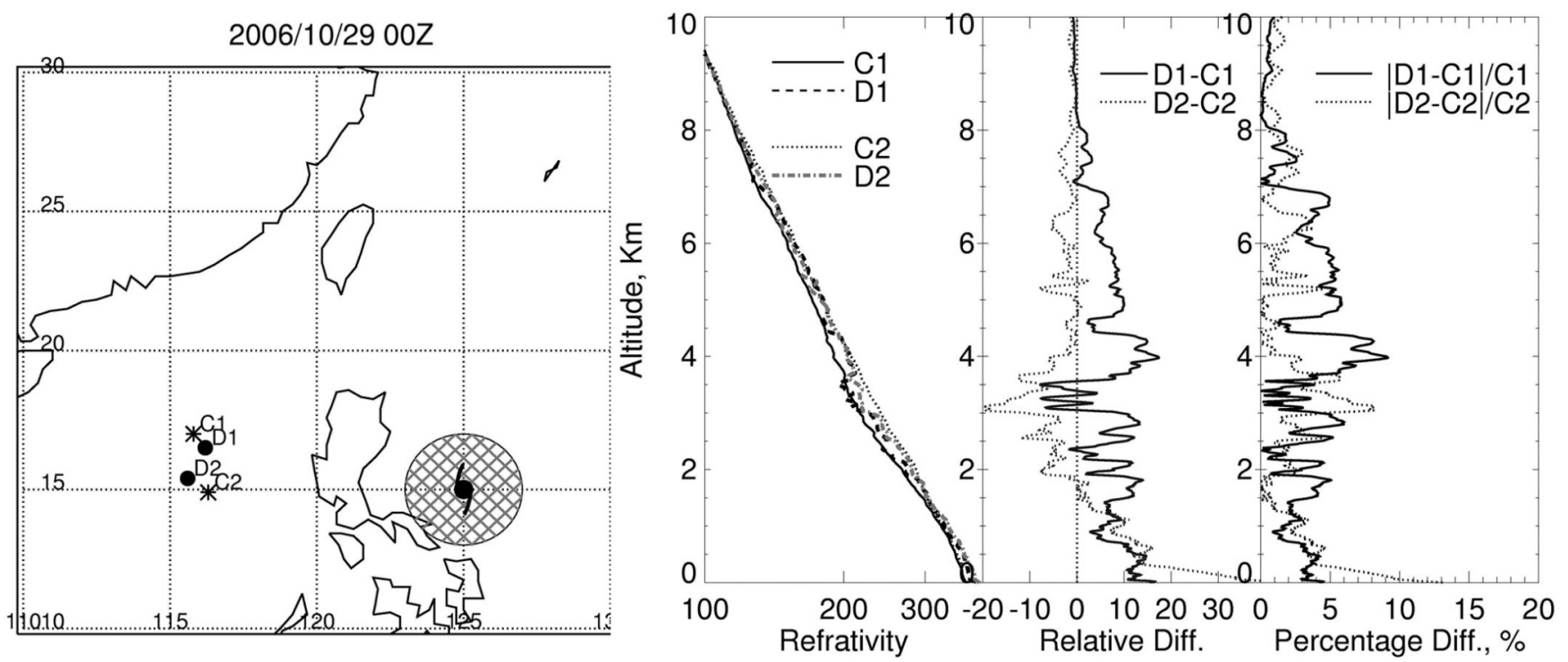

Fig. 12. The left panel shows the positions of two FORMOSAT-3 RO events (solid circles marked as C1 and C2) and two dropsonde events (open circles marked as D1 and D2) obtained from the airplane operation on 29 October 2006. The left figure in the right panel shows the refractivity in logarithmic scale versus altitude for the FORMOSAT-3 events (C1 and C2) and dropsonde events (D1 and D2). The middle figure in the right panel shows D1 - C1 (solid line) and D2 - C2 (dotted line). The right figure in the right panel shows $100 * \mid(\mathrm{D} 1$ - C1) / C1| (solid line) and $100 * \mid(\mathrm{D} 2$ - C2) / C2 (dotted line).
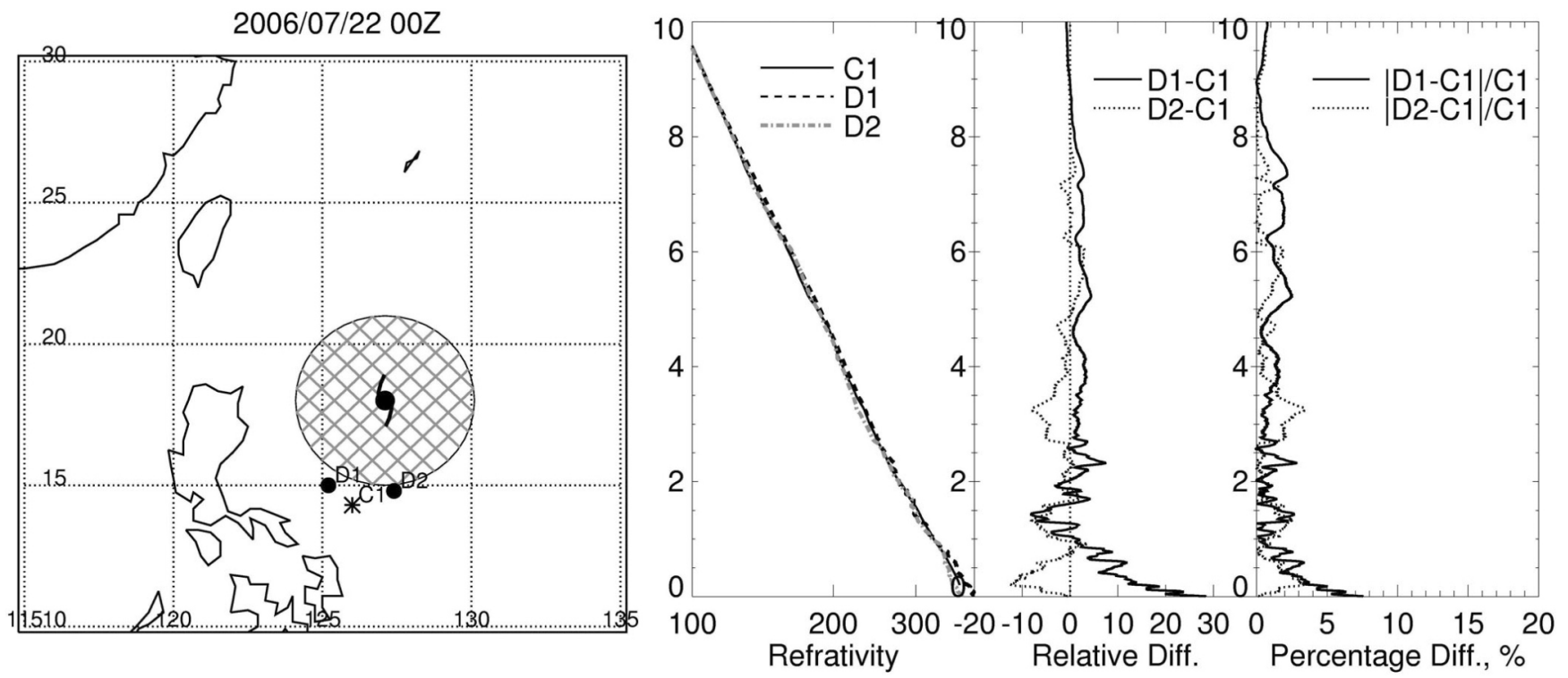

Fig. 13. The left panel shows the positions of a FORMOSAT-3 RO event (red solid circle, marked as C1) and several dropsonde events during the Kamei typhoon on 22 July 2006. The left figure in the right panel shows the refractivity in logarithmic scale versus altitude for the FORMOSAT-3 event (C1) and two dropsonde events (open circles, marked as D1 and D2). The middle figure in the right panel shows D1 - C1 (solid line) and D2 - C2 (dotted line). The right figure in the right panel shows $100 *|(\mathrm{D} 1-\mathrm{C} 1) / \mathrm{C} 1|$ (solid line) and $100 *|(\mathrm{D} 2-\mathrm{C} 2) / \mathrm{C} 2|($ dotted line).

total pressure and water vapor pressure in mbar, respectively. The time sampling of the dropsonde is 0.5 seconds. Based on the dropsonde instrument specification provided by the manufacturer, Vaisala Corp., the dropsonde has a $0.2^{\circ} \mathrm{C}$ and $2 \%$ accuracy on its THERMOCAP capacitive temperature sensor and H-HUMICAP thin film capacitor humidity sensor individually. Here, we use the ASPEN (Atmospheric Sounding Processing ENvironment) software designed by NCAR to process the original dropsonde profile for our data study. The vertical resolution of temperature and humidity data from the dropsonde is $10 \mathrm{~m}$ on average. The temperature sensor is made of fine platinum 
wire with a reflective coating to minimize heating from sunlight and the retention of water droplets. The dropsondes used around the circulation of typhoons (Wu et al. $2005 \mathrm{~b}$ ) have reasonable sounding profiles for weather diagnosis and model assimilation. We found the dropsonde works well under general and severe weather conditions. The middle figure in the right panel of Fig. 12 shows the difference in refractivity (solid line is D1 - $\mathrm{C} 1$ and dotted line is D2 - C2) between the FS-3 RO refractivity and the dropsonde measurements. The maximum difference in refractivity is about 10 below $4 \mathrm{~km}$ altitude except near the ground for D2 - C2. The right figure in the right panel of Fig. 12 shows the absolute value of the difference in refractivity divided by the FORMOSAT- 3 refractivity values (the solid line is $100 *|(\mathrm{D} 1-\mathrm{C} 1) / \mathrm{C} 1|$ and the dotted line is $100 *|(\mathrm{D} 2-\mathrm{C} 2) / \mathrm{C} 2|)$. We see that the difference is about $5 \%$ or less on average, but is larger (about $8 \%$ ) at about 3 $4 \mathrm{~km}$ altitude. Thus, based on these comparisons we conclude that the FS-3 RO retrieval profiles are reasonably accurate even during a severe weather condition. Due to a limited budget only a few dropsonde flights were carried out. Also, the FS-3/C RO data density is still quite low with an average distance between neighboring profiles at $\sim 400 \mathrm{~km}$ when considering one day's RO data. Thus, only 4 cases with reasonably close co-locations are reported in this section. However, more comparisons should be carried out to reach a more definitive conclusion.

In order to check the accuracy of GPS RO sounding profiles in severe weather conditions, we performed cross data validation between the GPS RO sounding profiles and direct measurements of atmospheric profiles during the Kamei typhoon on 22 July 2006. The left panel of Fig. 13 shows the locations of two dropsonde measurements (open circles marked as D1 and D2) and one FS-3 RO event (solid circle marked as $\mathrm{C} 1$ ). The distance between the dropsonde measurements and the FS-3 RO event is about $100 \mathrm{~km}$, and the time difference is about one hour. The left figure in the right panel of Fig. 13 shows the comparison between the refractivity profiles obtained from the atmospheric parameters measured by dropsondes (via the empirical formula) and the FS-3 RO refractivity profile. The middle figure in the right panel of Fig. 13 shows the difference in refractivity (solid line is D1 - C1 and dotted line is D2 - C1) between the FS-3 RO refractivity and that obtained from the dropsonde weather measurements. The maximum difference in refractivity is less than about 3 . The right figure in the right panel of Fig. 13 shows the absolute value of the difference in refractivity divided by the FORMOSAT-3 refractivity values (the solid line is $100 *|(\mathrm{D} 1-\mathrm{C} 1) / \mathrm{C} 1|$ and the dotted line is $100 *|(\mathrm{D} 2-\mathrm{C} 1) / \mathrm{C} 1|)$. We see that the percentage difference is about $3 \%$ or less except near the ground where the percentage difference is about $5 \%$. Thus, we conclude that the FS-3 RO sounding profiles are quite accurate.

\section{ERROR ANALYSIS}

The well-detailed RO retrieval method had been published in many papers, especially by the UCAR COSMIC group (Kursinski et al. 2000; Kuo et al. 2004). Here, we simply introduce the RO data processing method to explain the source of an RO error more clearly. The data processing includes several main steps. First, we derive the Doppler shift from the RO observations. Then, we calculate the bending angle, and then derive the refraction $(n)$ profiles by the following equation:

$n\left(a_{0}\right)=\exp \left\{\frac{1}{\pi} \int_{a_{\text {Top }}}^{\infty} \frac{\alpha(a)}{\sqrt{a^{2}-a_{0}^{2}}} d a\right\} \exp \left\{\frac{1}{\pi} \int_{a_{0}}^{a_{\text {Top }}} \frac{\alpha(a)}{\sqrt{a^{2}-a_{0}^{2}}} d a\right\}$

where $\alpha(a)$ is the bending angle, $a$ is the impact parameter which is equal to the refraction multi radius $(r)$ from the earth center, the subscript of "Top" indicates the top boundary that RO could observe or would be chosen by optimization purpose. The refractivity $N$ is calculated by

$N=10^{6}(n-1)$

The pressure $P(z)$ could be derived by the following gravity force balance equation:

$P\left(z_{0}\right)=\frac{1}{77.6 R} \int_{z_{0}}^{z_{\text {Top }}}-g N(z) d z+P\left(z_{\text {Top }}\right)$

where $R$ is the mix value between the dry specific constant $[R d: 461.52 \mathrm{~J} /(\mathrm{Kg} \cdot \mathrm{K})]$ and the water vapor specific constant $[R v: 461.52 \mathrm{~J} /(\mathrm{Kg} \cdot \mathrm{K})]$. In the initial processing in RO retrieval, the contribution of water vapor is ignored and $R$ will be set to equal to $R d$. The dependence of refractivity on pressure ( $P$ in mbar), temperature ( $T$ in Kelvin) and vapor pressure ( $e$ in mbar) is taken from the empirical formula:

$N=77.6 \frac{P}{T}+373000 \frac{e}{T^{2}}$

The dry temperature in atmPrf files is derived by ignoring the water vapor pressure in the above equation. In order to obtain the correct temperature, the above formula is rewritten as

$T=\frac{77.6 P}{N-373000 \frac{e}{T^{2}}}$

where $T$ on the right hand side of the equation is taken as the dry temperature. Thus, the dry temperature would be lower than a true temperature including the effect of water vapor. 
Kuo et al. (2004) mentioned that the magnitude of a bending angle and the neutral atmosphere-related variations decrease exponentially with altitude, thus, the magnitude of noise remains roughly constant and overshadows the signal above a certain altitude. In order to reduce the error propagation from high to low altitude after the Abel inversion, the UCAR group uses models and cost functions to optimize the bending angle. The optimal bending angle profile is (Kuo et al. 2004):

$\alpha_{\text {opt }}(a)=w_{\text {obs }}(a) \alpha_{\text {obs }}(a)+w_{\text {guess }}(a) \alpha_{\text {guess }}(a)$

where $\alpha_{\text {guess }}(a)$ is calculated by models, the weighting functions $w_{\text {obs }}(a)$ and $w_{\text {guess }}(a)$ are determined by the bending angle observation quality. The model for $\alpha_{\text {guess }}(a)$ is based on the atmospheric NCEP in near-real time data processing, and the atmospheric ECMWF model in post data processing.

We compare the observed bending angles and the optimal bending angles in the atmPrf files obtained by the UCAR COSMIC group by using the bending angle data from Day 200, 2006 to Day 289, 2006, and the total RO number is 102954. Figure 15 shows the Mean Bias Ratio $(M B R)$ in the left panel and the standard deviation in the right panel of $M B R$ (std.MBR) at different altitude versus latitude for 90 days, and the $M B R$ formula is given by

$\operatorname{MBR}(z)=100\left(\sum_{i=1}^{N} \frac{\alpha_{o b s}(z)-\alpha_{o p t}(z)}{\alpha_{o p t}(z)}\right) / N$

and $s t d . M B R$ is calculated by

$\operatorname{std} \cdot \operatorname{MBR}(z)=\left\{\sum_{i=1}^{N}\left[100 \frac{\alpha_{o b s}(z)-\alpha_{o p t}(z)}{\alpha_{o p t}(z)}-\operatorname{MBR}(z)\right]^{2}\right\} / N$
The statistics is calculated for every 10-degree interval in latitude. According to the results of atmPrf retrieved by the UCAR COSMIC group, the weighting function $w_{\text {guess }}$ in Eq. (7) is zero below $20 \mathrm{~km}$ in altitude, and the observed bending angle is used to derive the atmospheric parameter profiles. The left panel of Fig. 14 shows the mean bias ratio (MBR in \%) versus latitude (global) and the bias is very small at $30 \mathrm{~km}$ altitude. $M B R$ becomes bigger $(\sim 2 \%)$ around a southern polar region at $35 \mathrm{~km}$ altitude, and at 40 $\mathrm{km}$ altitude $M B R$ has two peaks $(\sim 1 \%)$ on both sides of the equator and also bigger bias in a northern polar region. The results show that the bias above $20 \mathrm{~km}$ altitude is larger than zero and means that most observed bending angles are larger than the guessed bending angle. A larger bias also means that a higher weighting of the guessed bending angle is used. The right panel of Fig. 14 shows the standard deviation of $M B R$ ( $s t$. $M B R$ in \%) versus latitude at five different altitudes $(20,25,30,35$, and $40 \mathrm{~km})$ for an RO event bias. The solid line presents the RO number (scale is on the right vertical axis) for the statistics. The $s t d . M B R$ is very small $(<0.3 \%)$ below $25 \mathrm{~km}$ and becomes bigger at a higher altitude. At a higher altitude above $25 \mathrm{~km}$, the std.MBR has a local peak at $\sim 15$ degree latitude in the northern hemisphere, but becomes bigger in both northern and southern polar regions.

According to the integral formula found in Eq. (1), the bias at an upper altitude would influence the accuracy of refraction. Fortunately, the error influence decreases with the square root of $\left(a^{2}-a_{o}^{2}\right)$ which is larger for a refraction at lower altitude. The RO results at lower altitude should be more accurate if the water vapor doesn't exist. Above $\sim 25 \mathrm{~km}$, we should know how much the guessed bending angle is weighted.

In Eq. (4), the refractivity and pressure could be re-
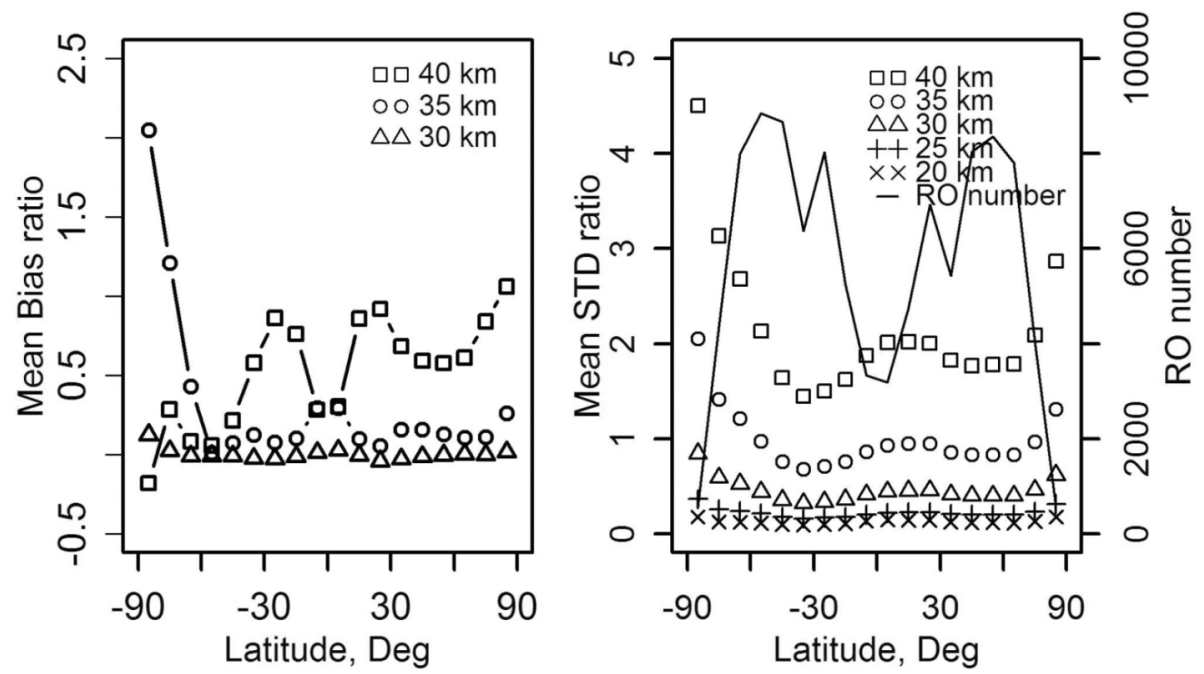

Fig. 14. The left panel shows the mean bias ratio (in \%) versus latitude from Day 200, 2006 to Day 289, 2006 at three different altitudes (30, 35, and $40 \mathrm{~km}$ ). The right panel shows the standard deviation (in a percentage) of RO event bias. 
trieved from Eqs. (2) and (3), respectively. There are still two unknown parameters (temperature and water vapor pressure) that should be solved. The water vapor pressure is ignored to obtain dry temperature in atmPrf, the other information is then added to derive both water vapor pressure and wet temperature as given in Eq. (5). The 1D VAR retrieval of wet temperature and water vapor was discussed by Engeln et al. (2003). The 1D VAR retrieval method is used when water vapor exists, so it is always used at lower altitude. Because the true value of $R$ in Eq. (3) is replaced by $R d$, iteration should be performed to improve pressure and wet temperature and water vapor simultaneously and the accuracy of the model is critical for obtaining accurate water vapor pressure.

The other source of error in the RO retrieval scheme used in the present stage of FS-3 GOX operation is the use of the Abel transform (Kursinski et al. 2000) and the assumption that the atmospheric refractivity has a spherical symmetry without horizontal gradient and depends only on altitude. The correction due to the earth oblateness can be largely computed by redefining the center and radius of the sphere at the local RO event (Syndergaard 1998). However, the distributions of the atmospheric temperature, pressure and water vapor are not spherically symmetric and the refractivity varies in altitude, latitude and longitude and changes with different weather systems. The refractivity gradient in the horizontal direction is mainly due to a horizontal variation of water vapor below $5 \mathrm{~km}$ altitude and is the main source of error when the RO data is retrieved. The horizontal refractivity gradient in the ionosphere would also influence the accuracy of RO profiles especially above $30 \mathrm{~km}$. Because the refractivity above $30 \mathrm{~km}$ altitude is very small, a small error in that altitude region might cause large deviation relative to the true refractivity profiles. Moreover, the RO perigee point of the GPS ray at different height is not fixed in latitude and longitude as shown in Fig. 2. The upper panel of
Fig. 15 shows the horizontal span of latitude and longitude projection of all GPS RO retrieval vertical profiles obtained on 20 May 2007. Each horizontal span covers the perigee point projection of the RO vertical profiles from the lowest altitude to $20 \mathrm{~km}$ above the lowest altitude. The left panel of Fig. 15 shows the percentage of events versus the horizontal span and about $50 \%$ of the RO events have horizontal span between 1 and 2 degrees, which corresponds to a distance of 120 to $240 \mathrm{~km}$ on the earth surface. Thus, the horizontal span of the vertical profiles can be the major source of error in the RO retrieval scheme. This error should be addressed as a future improvement for the RO retrieval scheme.

\section{SUMMARY}

In this paper we have reported the status of the FORMOSAT-3/COSMIC mission and examined the quality of the GPS radio occultation retrieval of refractivity profiles obtained by the GOX receivers aboard the FORMOSAT-3/ COSMIC satellites. We have found that the quality and accuracy of FS-3/C and CHAMP RO data are similar, but the atmospheric RO soundings obtained by the FS-3 satellites in general penetrate to a lower altitude than CHAMP's. The lower atmospheric profiles are very important in analyzing water vapor data. We have also exercised an Intensive $\mathrm{Ob}$ servation Period (IOP) campaign to perform cross data validation of GPS RO refractivity profiles against refractivity obtained by the radiosonde (Wang and Lin 2007) and dropsonde measurements of atmospheric parameters via the empirical formula between refractivity and atmospheric parameters. Although only four collocated cases are presented, the refractivity obtained by GPS RO is quite consistent with refractivity computed from the dropsonde measurements, which implies the good quality of the FS-3 measurements. This indicates that the GPS RO retrieval of vertical re-
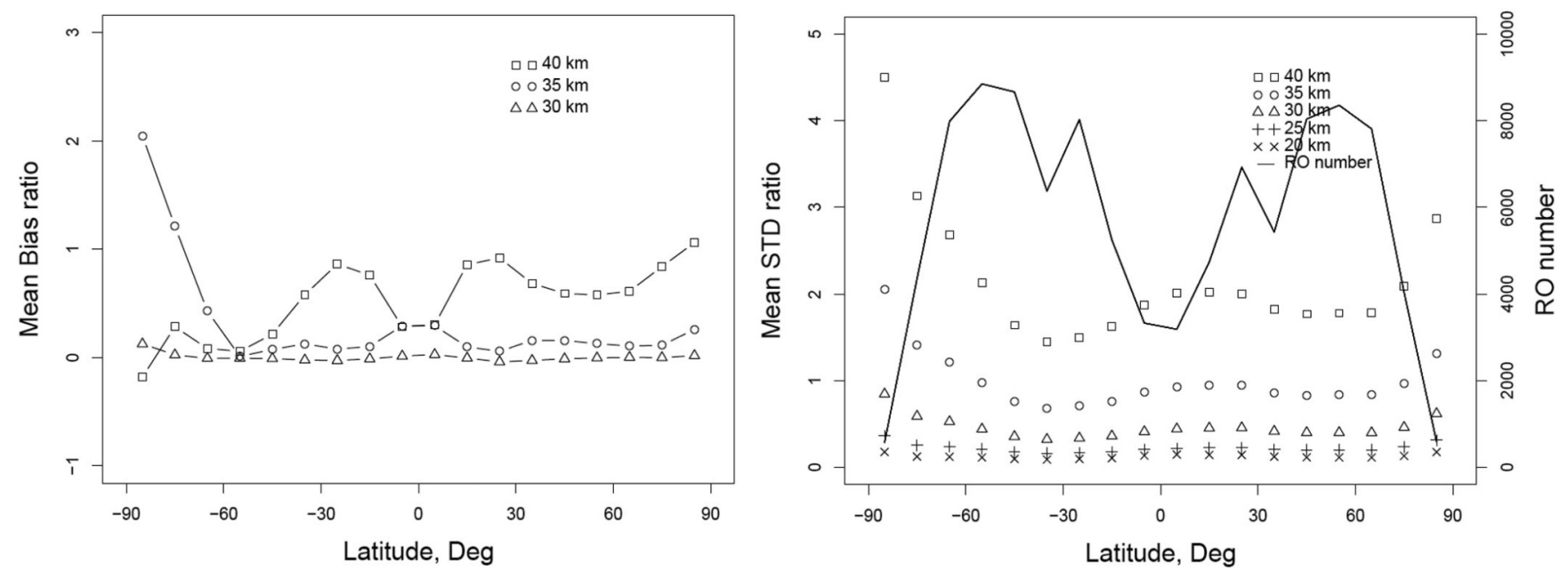

Fig. 15. The upper panel shows the global distribution of the horizontal span of the vertical profile of each FORMOSAT-3 RO event obtained on 20 May 2007. The left panel shows the percentage of the FORMOSAT-3 RO events versus the horizontal span of the vertical profiles. 
fractivity profiles obtained by the FS-3/C satellites is quite accurate and of high quality. In April, 2007 the total daily number of atmospheric RO soundings reached about 1800 2000. By the end of 2007 the orbit deployment of all six FORMOSAT-3 satellites should be complete, and we expect the total daily number of RO soundings to reach about 2500 , distributed nearly uniformly around the globe.

The FS-3/C weather data has been distributed to major weather research centers world-wide in near-real time. We expect that if a demonstration of near-real time operational use of RO sounding observations can be performed, FS-3/C will complement other Earth observing systems and improve global weather analyses and prediction. Because the FS-3/C mission will provide unprecedented amount of RO sounding data ( 2000 or more daily RO soundings distributed rather uniformly over the globe including the oceans and polar regions where there are insufficient weather data), the FS-3/C mission can potentially inaugurate an age of operational GPS sounding for weather forecasting, climate analysis and research, ionospheric monitoring, and a suite of related earth science pursuits.

Acknowledgement The most part of this article was done when I worked at NSPO, and was finished when I am PostDoc at Boston college.

\section{REFERENCES}

Anthes, R. A., C. Rocken, and Y. H. Kuo, 2000: Applications of COSMIC to meteorology and climate. Terr. Atmos. Ocean. Sci., 11, 115-156.

Beyerle, G., T. Schmidt, J. Wickert, S. Heise, M. Rothacher, G. Konig-Langlo, and K. B. Lauritsen, 2006: Observations and simulations of receiver-induced refractivity biases in GPS radio occultation. J. Geophys. Res., 111, D12, D12101, doi: 10.1029/2005JD006673. [Link]

Cheng, C. Z., Y. H. Kuo, R. A. Anthes, and L. Wu, 2006: Satellite constellation monitors global and space weather, EOS, Trans. $A G U, \mathbf{8 7}, 166$, doi:10.1029/2006EO170003. [Link]

Engeln, A. V., G. Nedoluha, G. Kirchengast, and S. Buehler, 2003: One-dimensional variational (1-D Var) retrieval of temperature, water vapor, and a reference pressure from radio occultation measurements: A sensitivity analysis. $J$. Geophys. Res., 108, D11, 4337, doi: 10.1029/2002JD 002908. [Link]

Gurvich, A. S., M. E. Gorbunov, and L. Kornblueh, 2006: Comparison between refraction angles measured in the Microlab-1 experiment and calculated on the basis of an atmospheric general circulation model. Izv. Atmos. Ocean. Phys., 42, 709-714, doi:10.1134/S0001433806060053. [Link]
Kuo, Y. H., T. K. Wee, S. Sokolovskiy, C. Rocken, W. Schreiner, D. Hunt, and R. A. Anthes, 2004: Inversion and error estimation of GPS radio occultation data. J. Meteorol. Soc. Jpn., 82, 507-531, doi: 10.2151/jmsj.2004.507. [Link]

Kursinski, E. R., G. A. Hajj, S. S. Leory, and B. Herman, 2000: The GPS radio occultation technique. Terr. Atmos. Ocean. Sci., 11, 53-114.

Rocken, C., Y. H. Kuo, W. S. Schreiner, D. Hunt, S. Sokolovskiy, and C. McCormick, 2000: COSMIC system description. Terr. Atmos. Ocean. Sci., 11, 21-52.

Sokolovskiy, S., Y. H. Kuo, C. Rocken, W. S. Schreiner, and D. Hunt, 2006a: Monitoring planetary boundary layer by GPS radio occultation signals recorded in the open-loop mode. Geophys. Res. Lett., 33, L12813, doi: 10.1029/ 2006GL025955. [Link]

Sokolovskiy, S., C. Rocken, D. Hunt, W. Schreiner, J. Johnson, D. Masters, and S. Esterhuizen, 2006b: GPS profiling of the lower troposphere from space: Inversion and demodulation of the open-loop radio occultation signals. Geophys. Res. Lett., 33, L14816, doi: 10.1029/2006GL026112. [Link]

Syndergaard, S., 1998: Modeling the impact of the Earth's oblateness on the retrieval of temperature and pressure profiles from limb sounding. J. Atmos. Sol.-Terr. Phys ., 60, 171-180, doi: 10.1016/S1364-6826(97)00056-4. [Link]

Wang, K. Y. and S. C. Lin, 2007: First continuous GPS soundings of temperature structure over antarctic winter from FS-3/C constellation. Geophys. Res. Lett., 34, L12805, doi: 10.1029/2007GL030159. [Link]

Wickert, J., Ch. Reigber, G. Beyerle, R. Koig, C. Marquardt, T. Schmidt, L. Grunwaldt, R. Galas, T. Meehan, W. Melbourne, and K. Hocke, 2001: Atmosphere sounding by GPS radio occultation: First results from CHAMP. Geophys. Res. Lett., 28, 3263-3266, doi: 10.1029/2001GL 013117. [Link]

Wickert, J., T. Schmidt, G. Beyerle, S. Heise, and C. Reigber, 2006: Global atmospheric sounding with GPS radio occultation with CHAMP. In: Flury, J., R. Rummel, C. Reigber, M. Rothacher, G. Boedecker, and U. Schreiber, (Eds.), Observation of the Earth System from Space, Springer, 389-412.

Wu, B. H., V. Chu, P. Chen, and T. Ting, 2005a: FS-3/C science mission update. GPS Solut., 9, 111-121, doi: 10.1007/ s10291-005-0140-z. [Link]

Wu, C. C., P. H. Lin, S. Aberson, T. C. Yeh, W. P. Huang, K. H. Chou, J. S. Hong, G. C. Lu, C. T. Fong, K. C. Hsu, I. I. Lin, P. L. Lin, and C. H. Liu, 2005b: Dropwindsonde observations for typhoon surveillance near the Taiwan region (DOTSTAR): An overview. Bull. Amer. Meteor. Soc., 86, 787-790, doi: 10.1175/BAMS-86-6-787. [Link] 